\title{
Frailty and mortality among older patients in a tertiary hospital in Nigeria
}

\author{
Lawrence. A. Adebusoye ${ }^{1}$, Eniola. O. Cadmus $^{2}$, Mayowa. O. Owolabi ${ }^{3}$ and Adesola Ogunniyi ${ }^{3}$
}

Ghana Med J 2019; 53(3):210-216 doi: http://dx.doi.org/10.4314/gmj.v53i3.5

\author{
${ }^{1}$ Chief Tony Anenih Geriatric Centre (CTAGC), University College Hospital, Ibadan, Nigeria \\ ${ }^{2}$ Department of Community Medicine, College of Medicine, University of Ibadan, Nigeria \\ ${ }^{3}$ Department of Medicine, College of Medicine, University of Ibadan, Nigeria
}

Corresponding author: Dr. Lawrence. A. Adebusoye

E-mail: larrymacsoye@yahoo.com

Conflict of interest: None declared

\begin{abstract}
SUMMARY
Background: This study determined the frailty status and its association with mortality among older patients.

Design: A prospective cohort design.

Setting: Study was conducted at the medical wards of University College Hospital, Ibadan, Nigeria.

Participants and study tools: Four hundred and fifty older patients ( $>60$ years) were followed up from the day of admission to death or discharge. Information obtained includes socio-demographic characteristics and clinical frailty was assessed using the Canadian Study of Health and Aging (CSHA) scale. Bivariate and multivariate analyses were carried out using SPSS version 21 at a $\mathrm{p}<0.05$.

Results: Overall, frailty was identified in $285(63.3 \%)$ respondents. Mortality was significantly higher among frail respondents $(25.3 \%)$ than non-frail respondents $(15.4 \%) \mathrm{p}=0.028$. Logistic regression analysis showed factors associated with frailty were: male sex $(\mathrm{OR}=1.946$ [1.005-3.774], $\mathrm{p}=0.048)$, non-engagement in occupational activities $(\mathrm{OR}=2.642$ [1.394-5.008], $\mathrm{p}=0.003)$, multiple morbidities $(\mathrm{OR}=4.411$ [1.944-10.006], $\mathrm{p}<0.0001)$, functional disability $(\mathrm{OR}=2.114$ [1.029-4.343), $\mathrm{p}=0.042]$, malnutrition $(\mathrm{OR}=9.258$ [1.029-83.301], $\mathrm{p}=0.047)$ and being underweight $(\mathrm{OR}=7.462$ [1.499-37.037], $\mathrm{p}=0.014)$.

Conclusion: The prevalence of frailty among medical in-hospital older patients is very high and calls for its prompt identification and management to improve their survival.
\end{abstract}

Keywords: Frailty, Mortality, Older patients, in-hospital, Nigeria

Funding: The study was self-funded by the authors

\section{INTRODUCTION}

Frailty is a biological syndrome defined as "a state of vulnerability resulting from progressive, cumulative physiological declines in reserve capacity and fitness across multiple body systems". ${ }^{1,2}$ Frailty is characterized by a loss of physiological reserves and, consequently, an inability to maintain homeostasis to combat a disease or injury with the common signs and symptoms which include fatigue, weight loss, weakness, low activity level, slow motor performance, and cognitive loss. ${ }^{2,3}$

Research, however, suggests that frailty may be present in up to $50-80 \%$ of medical in-hospital older patients. ${ }^{3}$, ${ }^{4}$ Frail older persons have difficulty in coping with acute stressors such as hospitalization which often leads to poorer health outcomes. ${ }^{2}$ Two major frailty models have been described in the literature. ${ }^{5}$ First is the biologic syndrome model (frailty phenotype) described by Fried et al., which is suitable for the identification of non-disabled older persons at risk of negative events. ${ }^{6,7}$
The measure is based on having three or more components of five phenotypic criteria namely; weakness, slowness, low level of physical activity, self-reported exhaustion, and unintentional weight loss. ${ }^{5}$ Second is the burden model (the frailty index) which is cumulative of functional deficits identified in a comprehensive geriatric assessment. ${ }^{5-7}$ The frailty index quantifies the functional, physiologic and psychologic conditions in addition to ascertaining the effectiveness of interventions and health status trajectories especially during hospitalization of older persons. $^{2}$

Frailty is associated with mortality. ${ }^{3,8}$ Although research in high-income countries abounds, there is limited information in low and middle-income countries (LMICs). Nigeria alongside many countries of the world is also experiencing the global phenomenon of population ageing. However, ageing in Nigeria is occurring alongside weak health systems and service provisions which ill-equipped 


\section{Original Article}

her to cope with the high burden of hospitalization among frail older persons.

This prospective cohort study aimed to determine the frailty status and mortality among older patients admitted to the medical wards of a tertiary hospital in Nigeria. Information thereby obtained would assist in developing interventions targeted at complementing the clinical management of older patients while improving their survival during hospitalization.

\section{METHODS}

\section{Study site}

This study which was part of a large project on the mortality among older patients and has been previously reported. ${ }^{9}$ Briefly, data were collected from patients in the medical wards of the University College Hospital (UCH), Ibadan. UCH is the first tertiary hospital in Nigeria founded in 1957 and has 1000 beds. Medical outpatients' clinics, Emergency Department, and General outpatients' clinic are the gateways for the admission of older patients to the medical wards which have 150 beds covering the major specialties (gastroenterology, pulmonology, infectious diseases, neurology, cardiology, nephrology, dermatology, and endocrinology). Medical in-hospital older patients are managed by consultant physicians and resident doctors.

\section{Study population}

A total of 450 older male and female older patients $(\geq 60$ years) admitted to the medical wards were enrolled during the study period (May 2013 and November 2014) consecutively. The sample size was derived using the prevalence value for the best estimate of mortality among older patients admitted to medical wards in Nigeria. ${ }^{10}$ The ages of the respondents were determined by the direct recall and by the table of historical events if they could not recall their ages. ${ }^{11,12}$ Proxies who included the caregivers and close relations were interviewed in place of older patients who were too ill, unconscious or aphasic. Those who did not give their consent were excluded from the study.

\section{Study design}

This was a prospective cohort study. Patients aged 60 years and above who admitted in the medical wards were recruited and followed-up. Patients' recruitment was between May 12th, 2013 and November 30th, 2014. Subsequently, all patients who met the inclusion criteria were recruitment consecutively until the desired sample size was attained.

Respondents were observed from day of admission till discharged or death. At admission, each patient had baseline investigation such as full blood count, urinalysis and fasting plasma glucose. Frailty assessed within the first 24 hours of admission. Clinical parameters such as blood pressure, pulse rate and temperature were taken each day.

\section{Instrument}

A pretested, semi-structured, interviewer-administered questionnaire was utilized for the data collection. Information obtained included sociodemographic characteristics and clinical profile. In addition, the Canadian Study of Health and Aging (CSHA) clinical frailty scale was used to assess the frailty among the respondents. ${ }^{13}$ The frailty scale is an effective measure of frailty index and provides predictive information similar to that of other established tools about mortality. ${ }^{13}$ It is rated from $1=$ very fit to $7=$ severely frail based on the clinical profile of the patients. ${ }^{13}$

Furthermore, the ten-item Barthel's basic activities of daily living (BADL) tool was used to assess the functional disability. ${ }^{14}$ Functional disability was defined as needing assistance in at least one of the basic activities of daily living. ${ }^{15}$ The Short Form -12 version 2 health survey (SF-12V2) was employed to measure the quality of life of the respondents.16 The physical component summary (PCS) and mental component summary (MCS) scores of the SF-12 were dichotomized at the mean scores (high vs. low) $(\mathrm{PCS}=36.5$; $\mathrm{MCS}=42.5) .{ }^{17}$ The 'six-item screener' which is a brief and reliable instrument with diagnostic properties comparable to the full Folstein's Mini-mental state examination (MMSE) was used for the assessment of cognition. 18 Malnutrition was assessed using the 'Mini-nutritional assessment- short form' (MNA-SF). MNA-SF had been used previously among older Nigerians. ${ }^{19,20}$

The level of generalized anxiety and depression was measured with the 'Hospital Anxiety and Depression Scale' (HADS), a 14-item tool (seven questions each for generalized anxiety and depression). ${ }^{21,22}$ The questionnaire was available in both English and the local language (Yoruba). The instrument was translated to Yoruba and back-translated to English to ensure the original meanings were maintained. Subsequently, the instrument was pretested in another facility apart from the study site. The questionnaire was administered in the patient's preferred language (English or Yoruba) by trained research assistants who were bilingual. Height was measured using a stadiometer (Seca, Hanover, USA) to the nearest 0.1 centimeters $(\mathrm{cm})$ and weight with weighing scale (Hana, Shenzhen, China) to the nearest 0.1 kilograms $(\mathrm{kg})$.

The body mass index (BMI) was calculated using weight $(\mathrm{kg})$ divided by height (meter) squared. BMI was then categorized as underweight $(<18.4 \mathrm{~kg} / \mathrm{m} 2)$, normal 
(18.5-24.9 kg/m2), overweight $(25.0-29.9 \mathrm{~kg} / \mathrm{m} 2)$ and obesity (BMI $\geq 30.0 \mathrm{~kg} / \mathrm{m} 2){ }^{23}$

\section{Ethical consideration}

Approval for the study was obtained from the University of Ibadan/University College Hospital Institutional Review Board (UI/EC/12/0390). Each respondent/ proxy gave informed consent before the interview.

\section{Statistics}

Data entry, cleaning, and analysis were carried out using the Statistical Package for Social Sciences version 21 (SPSS 21). Descriptive analysis was carried out and appropriate charts were used to illustrate categorical variables. Chi-square statistics and student t-test were used to test associations between categorical variables and continuous variables respectively. The relationship between significant variables at bivariate analysis and the outcome measure, frailty were explored using the logistic regression analysis at $\mathrm{p}<0.05$.

\section{RESULTS}

A total of 450 older patients were recruited with a mean age of $71.5( \pm 8.0)$ years and female to male ratio of 1.08. Two hundred and eighty-five (63.3\%) respondents had frailty and $14 \%$ were rated as having severe frailty. As shown in Figure 1, a higher proportion of males (30.5\%) had mild frailty, while a higher proportion of females $(25.8 \%)$ was apparently vulnerable to frailty.

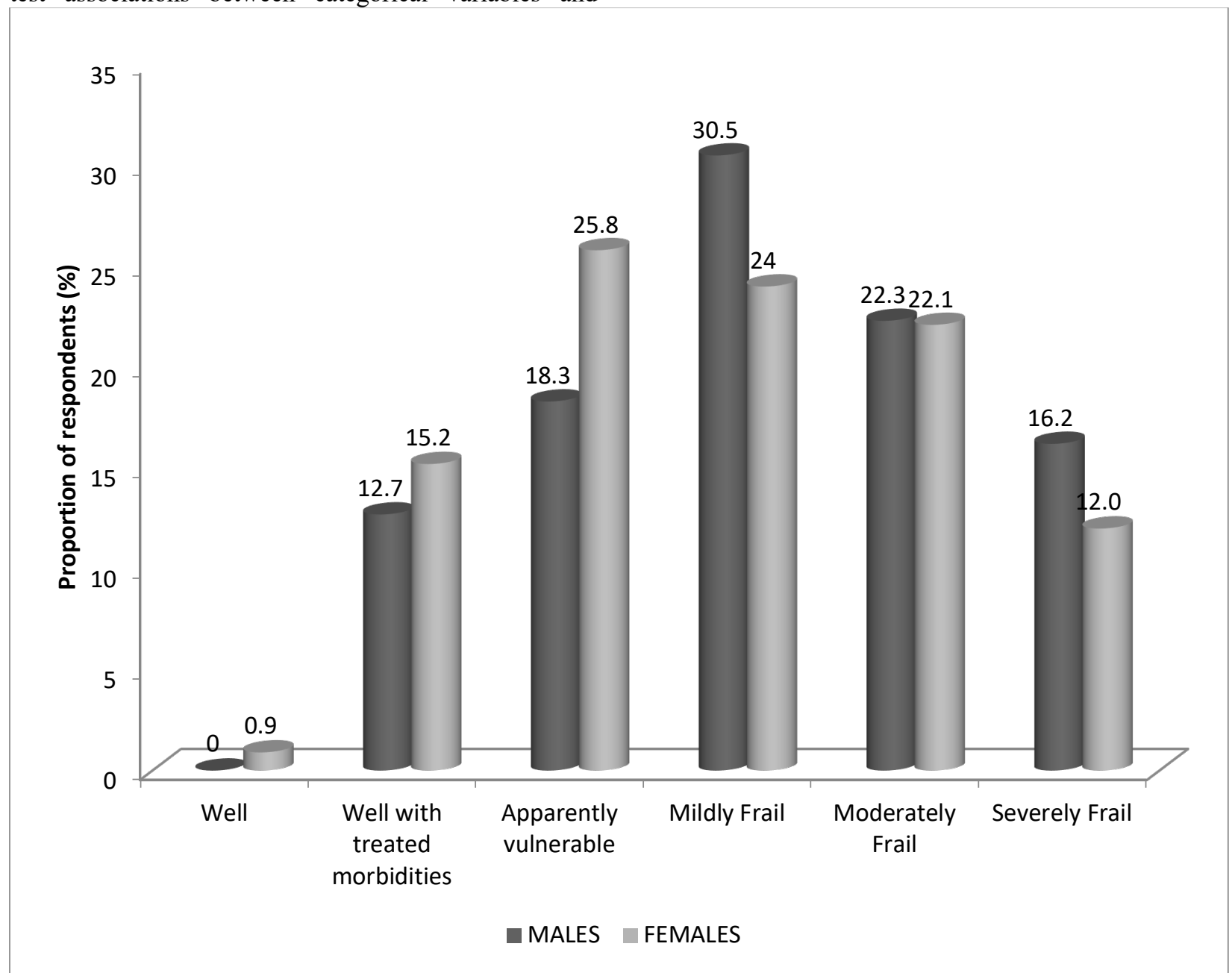

Figure 1 The frailty status of the respondents by sex

Other sociodemographic characteristic factors which were significantly associated with frailty included increasing age $(p=0.006)$, male sex $(p=0.017)$, higher educational status $(\mathrm{p}=0.036)$, non-engagement in occupational activities $(\mathrm{p}=0.002)$ and lower social classes $(\mathrm{p}$ $=0.013)$. See Table 1 . 
Table 1 Sociodemographic characteristics by the frequency of frailty

\begin{tabular}{|c|c|c|c|c|c|}
\hline Variable & $\begin{array}{l}\text { Frail=285 } \\
\text { n (\%) }\end{array}$ & $\begin{array}{l}\text { Not frail =165 } \\
\text { n (\%) }\end{array}$ & $\begin{array}{l}\text { Total=450 } \\
\text { N (\%) }\end{array}$ & $\chi^{2}$ & p \\
\hline \multicolumn{6}{|l|}{ Age (years) } \\
\hline $60-64$ & $48(50.5)$ & $47(49.5)$ & $95(100.0)$ & 12.593 & $0.006^{*}$ \\
\hline $65-69$ & $60(58.8)$ & $42(41.2)$ & $102(100.0)$ & & \\
\hline $70-74$ & $62(68.1)$ & $29(31.9)$ & $91(100.0)$ & & \\
\hline$\geq 75$ & $115(71.0)$ & $47(29.0)$ & $162(100.0)$ & & \\
\hline \multicolumn{6}{|l|}{ Sex } \\
\hline Male & $149(69.0)$ & 67 (31.0) & $216(100.0)$ & 5.706 & $0.017 *$ \\
\hline Female & $136(58.1)$ & $98(41.9)$ & $234(100.0)$ & & \\
\hline \multicolumn{6}{|l|}{ Marital status } \\
\hline Currently married & $199(69.8)$ & $110(30.2)$ & $309(100.0)$ & 0.484 & 0.487 \\
\hline Not currently married & $86(61.0)$ & $55(39.0)$ & $141(100.0)$ & & \\
\hline \multicolumn{6}{|l|}{ Highest educational attainment } \\
\hline None & $68(64.2)$ & $38(35.8)$ & $106(100.0)$ & 8.538 & $0.036^{*}$ \\
\hline Primary & $57(54.8)$ & $47(45.2)$ & $104(100.0)$ & & \\
\hline Secondary & $82(61.7)$ & $51(38.3)$ & $133(100.0)$ & & \\
\hline Tertiary & $79(73.8)$ & $28(26.2)$ & $107(100.0)$ & & \\
\hline \multicolumn{6}{|l|}{ Number of Children alive $(N=436) \Phi$} \\
\hline$\leq 2$ & $22(55.0)$ & $18(45.0)$ & $40(100.0)$ & 3.899 & 0.142 \\
\hline $3-4$ & $73(58.4)$ & $52(41.6)$ & $125(100.0)$ & & \\
\hline$\geq 5$ & $181(66.8)$ & $90(33.2)$ & $271(100.0)$ & & \\
\hline \multicolumn{6}{|l|}{ Occupational status } \\
\hline Still engaged in occupational activities & $66(52.8)$ & $59(47.2)$ & $125(100.0)$ & 9.827 & $0.002 *$ \\
\hline Not engaged in occupational activities & $223(68.6)$ & $102(31.4)$ & $325(100.0)$ & & \\
\hline \multicolumn{6}{|l|}{ Social class $(N=125)$} \\
\hline Upper (classes I - III) & $15(37.5)$ & $25(62.5)$ & $40(100.0)$ & 6.131 & $0.013^{*}$ \\
\hline Lower (classes IV - V) & $52(61.2)$ & $33(38.8)$ & $85(100.0)$ & & \\
\hline
\end{tabular}

* Significant at $5 \%$ level of significance

$\mathbf{T}$ Could not be assessed in all the respondents

Overall, there were 99 (22.0\%) in-hospital deaths. The 30-day all-cause mortality rate was significantly higher among frail respondents [18.8 deaths per 1000 patientdays $(95 \%$ CI 14.0 - 24.2)] compared with non-frail respondents [11.3 deaths per 1000 patient-days (95\% CI $7.1-17.1)$ ]. The mortality rate ratio (MRR) was 1.648 (95\% CI $1.008-2.837), \mathrm{p}=0.048$.

Table 2 depicts the frailty status by the proportion of inhospital deaths. A significantly higher proportion of frail respondents $72(25.3 \%)$ died on hospital admission compared to respondents who were not frail $27(15.4 \%), \mathrm{p}=$ 0.028 .

Table 2 The frailty status by the proportion of in-hospital deaths

\begin{tabular}{|c|c|c|}
\hline & $\begin{array}{l}\text { DEAD } \\
=99 \\
\text { n }(\%)\end{array}$ & $\begin{array}{l}\text { DISCHARGED } \\
=351 \\
\text { n }(\%)\end{array}$ \\
\hline Well & $0(0.0)$ & $2(100.0)$ \\
\hline Well with Comorbidities & $11(17.5)$ & $52(82.5)$ \\
\hline Apparently vulnerable & $16(16.0)$ & $84(84.0)$ \\
\hline Mildly frail & $26(21.3)$ & $96(78.7)$ \\
\hline Moderately frail & $21(21.0)$ & $79(79.0)$ \\
\hline Severely frail & $25(39.7)$ & $38(60.3)$ \\
\hline$\chi^{2}=14.490 \quad \mathrm{df}=5$ & \multicolumn{2}{|c|}{$\mathrm{p}=0.010^{*}$} \\
\hline
\end{tabular}

*Significant at $5 \%$ level of significance
The relative risk for mortality among frail respondents was 1.76 (95\% CI $1.05-2.96)$. There was a significant increase in the proportion of in-hospital deaths with the frailty status $(\mathrm{p}=0.010)$

Table 3 shows the clinical parameters associated with frailty. These include: BMI $(p=0.028)$, malnutrition ( $p$ $=0.022)$, cognitive impairment $(\mathrm{p}<0.0001)$, functional disability $(\mathrm{p}<0.0001)$, self-reported physical inactivity ( $\mathrm{p}$ $=0.010)$, depression $(\mathrm{p}=0.007)$ and having $\geq 5$ morbidities $(p<0.0001)$ were statistically associated with frailty.

Table 4 shows the logistic regression analysis which was carried out on significant variables associated with frailty. The logistic model was statistically significant, $\chi 2$ $(17)=77.051, \mathrm{p}<0.0001$. The model explained $29.6 \%$ TOTALNagelkerke (R2) of the variance in frailty and correctly $\mathbf{N}(\%)$ classified $72.3 \%$ of cases. The most significant factors


$63(100.6$ I 1 $1.005-3.774], \mathrm{p}=0.048)$, not engaged in occupa100 (100tiognal activities (OR $=2.642$ [95\% CI $1.394-5.008], \mathrm{p}$ $122(100 \theta) 0.003)$, multiple morbidities $\geq 5(\mathrm{OR}=4.411[95 \% \mathrm{CI}$ $100(100.0 .944-10.006], \mathrm{p}<0.0001)$, functional disability $(\mathrm{OR}=$ $63(100.02 .114$ [95\% CI $1.029-4.343), \mathrm{p}=0.042$, malnutrition $(\mathrm{OR}=9.258[95 \%$ CI $1.029-83.301], \mathrm{p}=0.047$ and being underweight $(\mathrm{OR}=7.462$ [95\% CI $1.499-37.037$ ], $\mathrm{p}=0.014$. 
Table 3 Clinical parameters by the frequency of frailty

\begin{tabular}{|c|c|c|c|c|c|}
\hline Variable & $\begin{array}{l}\text { Frail = 285 } \\
\text { n (\%) }\end{array}$ & $\begin{array}{l}\text { Not frail =165 } \\
\text { n }(\%)\end{array}$ & $\begin{array}{l}\text { Total }=450 \\
\text { N (\%) }\end{array}$ & $\chi^{2}$ & $\mathbf{p}$ \\
\hline \multicolumn{6}{|c|}{ Body Mass Index $(n=424)$} \\
\hline Underweight & $5(41.7)$ & $7(58.3)$ & $12(100.0)$ & 9.119 & $0.028^{*}$ \\
\hline Normal & $104(64.6)$ & $57(35.4)$ & $161(100.0)$ & & \\
\hline Overweight & $88(59.5)$ & $60(40.5)$ & $148(100.0)$ & & \\
\hline Obese & $77(74.8)$ & $26(25.2)$ & $103(100.0)$ & & \\
\hline \multicolumn{6}{|c|}{ Nutritional status $(n=350)$} \\
\hline Malnourished & $15(93.8)$ & $1(6.2)$ & $16(100.0)$ & 5.289 & $0.022 *$ \\
\hline No malnutrition & $221(66.2)$ & $113(33.8)$ & $334(100.0)$ & & \\
\hline \multicolumn{6}{|c|}{ Cognitive function $(n=387)$} \\
\hline Impaired & $69(86.3)$ & $11(13.7)$ & $80(100.0)$ & 24.676 & $<0.0001^{*}$ \\
\hline Not impaired & $172(56.0)$ & $135(44.0)$ & $307(100.0)$ & & \\
\hline \multicolumn{6}{|c|}{ Functional disability } \\
\hline Independent & $29(39.2)$ & $45(60.8)$ & $74(100.0)$ & 22.701 & $<0.0001^{*}$ \\
\hline Dependent & $257(68.4)$ & $119(31.6)$ & $376(100.0)$ & & \\
\hline \multicolumn{6}{|c|}{ Self-reported physical activity level } \\
\hline Active & $252(61.3)$ & $159(38.7)$ & $411(100.0)$ & 6.580 & $0.010^{*}$ \\
\hline Not active & $32(82.1)$ & $7(17.9)$ & $39(100.0)$ & & \\
\hline \multicolumn{6}{|l|}{ Anxiety $(n=436)$} \\
\hline Yes & $232(64.3)$ & $129(35.7)$ & $361(100.0)$ & 1.817 & 0.178 \\
\hline No & $42(56.0)$ & $33(44.0)$ & $75(100.0)$ & & \\
\hline \multicolumn{6}{|c|}{ Depression $(n=436)$} \\
\hline Yes & $33(82.5)$ & $7(17.5)$ & $40(100.0)$ & 7.287 & $0.007 *$ \\
\hline No & $241(60.9)$ & $155(39.1)$ & $396(100.0)$ & & \\
\hline \multicolumn{6}{|c|}{ Quality of life (physical domain) } \\
\hline Low & $132(68.4)$ & $61(31.4)$ & $193(100.0)$ & 3.727 & 0.054 \\
\hline High & $153(59.5)$ & $104(40.5)$ & $257(100.0)$ & & \\
\hline \multicolumn{6}{|c|}{ Quality of life (mental domain) } \\
\hline Low & $141(63.5)$ & $81(36.5)$ & $222(100.0)$ & 0.006 & 0.938 \\
\hline High & $144(63.2)$ & $84(36.8)$ & $228(100.0)$ & & \\
\hline \multicolumn{6}{|c|}{ Multiple morbidities } \\
\hline $1-4$ & $207(58.0)$ & $150(42.0)$ & $357(100.0)$ & 21.292 & $<0.0001^{*}$ \\
\hline$\geq 5$ & $78(83.9)$ & $15(16.1)$ & $93(100.0)$ & & \\
\hline
\end{tabular}

* Significant at $5 \%$ level of significance T Could not be assessed in all the respondents

Table 4 Logistic regression analysis of factors which were significantly associated with frailty



* Significant at $5 \%$ level of significance 


\section{DISCUSSION}

This study provides much-needed information about the prevalence of frailty and associated factors among older persons on hospital admission in a tertiary institution in Nigeria. The prevalence of frailty among elderly varies across different settings. For instance, studies have shown that frailty is higher in the hospital than in the community ${ }^{5}$, among people of African descent compared to the Caucasians and geographical location (lowest prevalence obtained among the Europeans). ${ }^{5}$ However, documented variability in the findings of frailty may be due to differences in the definition and tools used for the surveys. ${ }^{5}$

Our reported prevalence of frailty $(63.3 \%)$ was similar to those from other low and medium income countries (LMICs) but was lower than the European reports. ${ }^{4,24,25}$ This finding may be attributable to the differences in the age definition of the elderly where the European studies used 65 years and the LMICs used 60 years. ${ }^{5}$ Most studies reported a higher prevalence of frailty among the older women which would appear different from our observations. ${ }^{5,6}$ However, our finding was in tandem with studies from other LMICs where a higher prevalence of frailty was reported among hospitalized older men than women. ${ }^{4,}{ }^{24}$ A possible reason for these observations is that older men have higher hospitalization rates with more severe and disabling conditions as some other authors have observed. ${ }^{4,24}$

Furthermore, in this study, age was observed to be significantly associated with frailty. This finding is supported by other research which highlights the significant decline in the physiology of the body system (homeostenosis) with age. ${ }^{26}$ In addition, old age is associated with increased prevalence of disability and the cumulative burden of diseases.7 The relative risk for mortality of 1.76 among the frail respondents in this study is comparable to the range of 1.36 to 5.52 documented among frail inhospital older patients in a recent systematic review. ${ }^{2}$ However, this finding is not surprising as frailty is characterized by multisystem dysregulations, leading to a loss of dynamic homeostasis, decreased physiologic reserve, and increased vulnerability for subsequent morbidity and mortality. ${ }^{5}$ Our report showed that despite differences in the settings, there is a similarity in the risk borne by the older patients on hospital admission if the similar frailty measure was used. These include the presence of multiple morbidities, male sex functional disability, malnutrition and sedentary lifestyle $(\mathrm{OR}=2.6)$ were the predictors of frailty. Though frailty is a distinct entity, this finding further reinforced the belief that there is significant overlap between the aforementioned factors and frailty. ${ }^{7}$ Frailty leads to significant physical and functional decline, and it is difficult to reverse.
There is, therefore, a need for healthcare workers to appreciate the challenges faced in managing acutely ill older patients. This necessitates holistic management in order to identify vulnerable older patients needing prompt medical attention during hospitalization.

\section{Strength and limitations}

This was a prospective cohort study which spanned all the major medical specialties. To our knowledge, this study is the first to document frailty and associated findings among hospitalized older patients in Nigeria. The hospital-based setting may account for the high prevalence of frailty in comparison to the findings among community-dwelling older persons.

\section{CONCLUSION}

The high prevalence of frailty among medical in-hospital older patients is a medical challenge. The finding of modifiable predictors such as multiple morbidities, malnutrition, functional disability and sedentary lifestyle calls for a concerted public health action to address these factors which could lead to or worsen hospitalization outcomes.

\section{REFERENCES}

1. Fried LP, Tangen CM, Walston J, Newman AB, Hirsch C, Gottdiener J, et al. Frailty in older adults: evidence for a phenotype. J Gerontol A Biol Sci Med Sci. 2001 Mar;56(3):M146-56.

2. Pereira AA, Borim FSA, Neri AL. Risk of death in elderly persons based on the frailty phenotype and the frailty index: a review study. Rev bras geriatr gerontol. 2017;20(2):273-85.

3. Oo MT, Tencheva A, Khalid N, Chan YP, Ho SF. Assessing frailty in the acute medical admission of elderly patients. $J R$ Coll Physicians Edinb. 2013;43(4):301-8.

4. Storti LB, Fabrício-Whebe SCC, Kusumota L, Rodrigues RAP, Marques S. Frailty of elderly patients admitted to the medical clinic of an emergency unit at a general tertiary hospital. Texto Context Enferm. 2013;22(2):452-459.

5. Chen X, Mao G, Leng SX. Frailty syndrome: An overview. Clin Interv Aging. 2014;9:433-41.

6. Cesari M, Gambassi G, van Kan GA, Vellas B. The frailty phenotype and the frailty index: different instruments for different purposes. Age Ageing. 2014 Jan;43(1):10-2.

7. Blaum CS. The intersection between comorbidity, multimorbidity and frailty. In: U13 Gemsstar Conference 2015. p. 1-15. Available from: https://www.americangeriatrics.org/sites/default/files/inline-files/caroline_blaum.pdf. Accessed 26-09-2018. 
8. Le Maguet P, Roquilly A, Lasocki S, Asehnoune K, Carise E, Saint Martin M, et al. Prevalence and impact of frailty on mortality in elderly ICU patients: A prospective, multicenter, observational study. Intensive Care Med. 2014;40(5):674-82.

9. Adebusoye LA, Owolabi M, Ogunniyi A. Predictors of mortality among older patients in the medical wards of a tertiary hospital in Nigeria. Aging Clin Exp Res. 2018; 1-9. Available at: https://doi.org/10.1007/s40520-018-0997-7

10. Sanya EO, Akande TM, Opadijo G, Olarinoye JK, Bojuwoye BJ. Pattern and outcome of medical admission of elderly patients seen at University of Ilorin Teaching Hospital, Ilorin. African J Med Med Sci. 2008;37(4):375-81.

11. Ogunniyi A, Osuntokun BO. Determination of ages of elderly Nigerians through historical events: validation of Ajayi-Igun 1963 listing. West Afr J Med. 1993;12(4):189-90.

12. Paraïso MN, Houinato D, Guerchet $M$, Aguèh V, Nubukpo P, Preux PM, et al. Validation of the use of historical events to estimate the age of subjects aged 65 years and over in Cotonou (Benin). Neuroepidemiology. 2010;35(1):12-6.

13. Rockwood K, Song X, MacKnight C, Bergman H, Hogan DB, McDowell I, et al. A global clinical measure of fitness and frailty in elderly people. CMAJ. 2005;173(5):489-95.

14. Collin C, Wade DT, Davies S, Horne V. The Barthel ADL Index: a reliability study. Int Disabil Stud. 1988;10(2):61-3.

15. Ajayi SA, Adebusoye LA, Ogunbode AM, Akinyemi JO, Adebayo AM. Profile and correlates of functional status in elderly patients presenting at a primary care clinic in Nigeria. African J Prim Heal Care Fam Med. 2015;7(1):1 - 7.

16. Ware J, Kosinski M, Keller SD. A 12-Item ShortForm Health Survey: construction of scales and preliminary tests of reliability and validity. Med Care. 1996 Mar;34(3):220-33.

17. Li C-L, Chang H-Y, Hsu C-C, Lu JR, Fang H-L. Joint predictability of health related quality of life and leisure time physical activity on mortality risk in people with diabetes. BMC Public Health. 2013;13:67.

18. Callahan CM, Unverzagt FW, Hui SL, Perkins AJ, Hendrie HC. Six-item screener to identify cognitive impairment among potential subjects for clinical research. Med Care. 2002 Sep;40(9):771-81.

19. Nzeagwu O, Uwaegbute A. Assessment of Nutritional Vulnerability of the Elderly using Mini Nutritional Assessment (MNA) Tool. Niger J Nutr Sci. 2010;31(2):39-47.

20. Adebusoye L.A, Ajayi I.O, Dairo M.D, Ogunniyi A. Factors associated with undernutrition and overweight in elderly patients presenting at a primary care clinic in Nigeria. South African Fam Pract. 2011;53(4): 355-60.

21. Stafford L, Berk M, Jackson HJ. Validity of the Hospital Anxiety and Depression Scale and Patient Health Questionnaire-9 to screen for depression in patients with coronary artery disease. Gen Hosp Psychiatry. 2007;29(5):417-24.

22. Ojagbemi A, Owolabi M, Akinyemi J, Ovbiagele B. Proposing a new stroke-specific screening tool for depression: Examination of construct validity and reliability. eNeurologicalSci. 2017;9:14-8.

23. WHO. Physical status: the use and interpretation of anthropometry. Report of a WHO Expert Committee. Vol. 854, World Health Organization technical report series. 1995. p. 1-452.

24. Oliveira DR, Bettinelli LA, Pasqualotti A, Corso D, Brock F, Erdmann AL. Prevalence of frailty syndrome in old people in a hospital institution. Rev Lat Am Enfermagem. 2013;21(4):891-8.

25. Juma S, Taabazuing M, Montero-Odasso M. Clinical Frailty Scale in an Acute Medicine Unit: a Simple Tool That Predicts Length of Stay. Can Geriatr J. 2016 Jun;19(2):34-9.

26. de Villiers L. Frailty. Contin Med Educ. 2013;31(10):353-7. Available from: http://www.cmej.org.za/index.php/cmej/article/view/2868/3235. Accessed 17-08-2018. 